\title{
EL ETERNO FEMENINO TRAS EL ESPACIO NARRATIVO: MARARÍA Y EL PAISAJE DE LANZAROTE
}

Tamara Santana Abreu

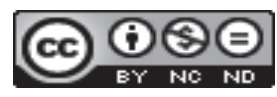

Doi: https://doi.org/10.15517/rfl.v46i1.41061

URL: https://revistas.ucr.ac.cr/index.php/filyling/index 



\title{
EL ETERNO FEMENINO TRAS EL ESPACIO NARRATIVO: MARARÍA Y EL PAISAJE DE LANZAROTE
}

\author{
ETERNAL FEMININE BEHIND NARRATIVE SPACE: \\ MARARÍA AND LANZAROTE'S LANDSCAPE
}

Tamara Santana Abreu

\begin{abstract}
RESUMEN
A lo largo de la historia, el discurso literario, preponderantemente masculino, ha consolidado todo un espectro de imágenes literarias alrededor de la mujer. Una de las representaciones inscritas en este imaginario es la de paisaje literario. Durante esta investigación, hemos parangonado la literaturización de la mujer con este concepto, atendiendo a una perspectiva de territorialidad respecto al personaje femenino y, en consecuencia, a la mujer real. Para presentar esta relación, hemos recurrido al concepto de simulacro (Baudrillard, 1978) y sus repercusiones reales. Luego, hemos desarrollado el angosto vínculo entre la representación literaria de la isla en su paisaje y la interpretación literaria de la mujer, apelando al término land-as-woman (Kolodny, 1973). Para ejemplificarlo, hemos analizado los distintos testimonios que estructuran la novela canaria Mararía (1975), de Rafael Arozarena, para concluir, por una parte, que feminizar el entorno robustece los roles genéricos adscritos al eterno femenino, luego a la mujer real, y por otra parte, que en los gobiernos conservaduristas, como sucede durante la dictadura franquista, el cuerpo de la mujer, con su potencial procreativo, pertenece al sistema natalista como el territorio pertenece a la patria.

Palabras clave: paisaje literario; personaje femenino; isla; mujer; literatura.
\end{abstract}

\begin{abstract}
Over the years, literary speech, predominantly masculine, has created a spectrum made of literary images around the woman. One of the representations which is part of her imaginery is the literary landscape. For this research, we have compared the literary woman with this concept, the literary landscape, according to a territorial perspective of woman's character and, therefore, to the real one. In order to show this relation, we have used the concept of simulacra (Baudrillard, 1978) and its real repercussions. Then, we have developed the link between the literary representation of the island in its own landscape and the literary interpretation of woman, by using the term land-aswoman (Kolodny, 1973). As an example, we have analyzed the testimonies which build the novel Mararía (1975), by Rafael Arozarena. Finally, we have concluded that feminizing the environment reinforces the gender roles which take part of the eternal feminine, so the real woman, as well as that conservative governments, such as the Spanish dictatorship after the civil war, the woman's body, due to its procreative potencial, belongs to the system as the soil belongs to the country.

Keywords: literary landscape; woman's character; island; woman; literature.
\end{abstract}

\footnotetext{
Mag. Tamara Santana Abreu. Estudiante del Doctorado en Estudios Lingüísticos y Literarios en sus Contextos Socioculturales. Universidad de Las Palmas de Gran Canaria. Las Palmas de Gran Canaria, Las Palmas, España.

Correo electrónico: tsabreu8.tsa@gmail.com

Recepción: 27- 11- 18

Aceptación: 26- 06- 19
} 
Cuando un escritor describe el territorio, desplaza la realidad para darle prioridad a su subjetividad. Entonces, su mirada interioriza lo externamente tangible en un proceso cognitivo que determina el espacio observado. Esta visión, irremisiblemente supeditada al prisma personal del individuo, queda plasmada como una verdad segmentada en las dimensiones textuales. La contextualiza de acuerdo con el contorno literario y la conceptualiza atendiendo a la literariedad del escenario a que se circunscribe. Luego, la realidad derramada en su escritura participa de la realidad absoluta a la par que disiente de ella, puesto que el territorio resulta desligado de su consideración original al convertirse en paisaje literario, siendo el paisaje una verdad a medias disgregada de la totalidad existente a las afueras del discurso. En este sentido, "[1]a naturaleza cambia de carácter al cambiar de escala" (Augé, 2013, p. 223). Pero no solo se altera la escala de la naturaleza tras acotarla en el universo textual, sino al apartar lo real para darle preferencia a lo literario.

Bien parecido es el proceso que el personaje femenino experimenta en la literatura. Si el paisaje literario consiste en la literaturización del externo real, la mujer interpretada por la voz transcrita del hombre no deja de ser un paisaje adaptado a la intencionalidad literaria del hacedor. Es decir: a partir de la realidad -la mujer concreta- origina un simulacro ${ }^{1}$-la mujer abstracta- que reproduce a la primera con la oblicuidad particular de quien escribe. Palabra mediante, el escritor imprime su mirada en el elemento contemplado, desliendo los márgenes entre la realidad y el enunciado. En consecuencia, lo intangible de la escritura queda adherido a lo tangible de la realidad y, al mismo tiempo, al imaginario colectivo, pues "la literatura dice del mundo, que al decir del mundo decide sus formalizaciones" (Marrero Henríquez, 2009, p. 11). Al igual que el paisaje reemplaza al espacio, este simulacro literario de la mujer reducida a objeto del discurso se propaga en detrimento de su identidad real. Y en postrera pero recalcitrante instancia, dota a un mito de la validez necesaria para arraigarse al patrimonio imaginario de un sistema cultural determinado -habida cuenta de que esta inercia literaria responde y proporciona contundencia al ideario imperante de la etapa histórica en que se establece.

En nuestro estudio, el panorama sociopolítico que nos interesa se concentra en la posguerra española, pues es el episodio nacional en que quedan constituidas las vicisitudes de la vida de nuestra protagonista. Mararía es una mujer procedente de la isla canaria de Lanzarote que, si bien consagrada en su juventud por su belleza, es progresivamente reprobada por una sociedad que no se encuentra en condiciones de entenderla. Realizaremos un recorrido por los testimonios de diversos personajes que componen el microcosmos del pueblo de Femés durante los años del gobierno nacionalsindicalista de Francisco Franco para elaborar una semblanza del personaje principal. Este análisis se estructura de acuerdo con distintos conceptos y estrategias discursivas, tales como la aculturación del territorio en consecuencia a la literaturización del paisaje, las nociones de simulacro e hiperrealidad (Baudrillard, 1978), land-as-woman (Kolodny, 1973) y la constitución cultural del género en el momento histórico pertinente. A continuación, atenderemos al paisaje literario que de la isla de Lanzarote, escenario correspondiente a la macroestructura global que nos concierne, se ha ido registrando en el imaginario colectivo y sus concomitancias con la novela de las letras canarias Mararía (1973).

1 En este sentido, apelaremos a la lectura que Baudrillard proporciona del concepto 'simulacro' disertado en su obra Cultura y simulacro (1978). 


\section{Mararía en el paisaje literario de la isla de Lanzarote}

En 1943 Rafael Arozarena escribe Mararía. Destinado a Lanzarote por trabajo y contando apenas veinte años, se encuentra con una anciana que no le parece en absoluto convencional para los tiempos que corren. Tanto es el interés que le despierta, que comienza a recopilar las vivencias de los vecinos de Femés para desentrañar el misterio que circunda a aquella mujer, de quien se desprende la incerteza del pasado y la verosimilitud de la leyenda. Sin embargo, el origen literario del personaje de Mararía no estriba en la prosa, sino en los versos titulados "María de Femés", incluidos en su obra A la sombra de los cuervos publicado en 19792.

Publicada por vez primera en 1973, Mararía se vertebra en 18 capítulos que van perfilando al personaje homónimo mediante los testimonios personales de quienes llegaron a conocerla. La protagonista es recordada como una muchacha dotada de una belleza tan prodigiosa que desataba pasiones en los hombres y reticencias en las mujeres. No obstante, el narrador se tropieza con ella en plena decrepitud, ya encarnada en el mito del pueblo de Femés. Su maltrecha apariencia y sus silentes apariciones impelen a este personaje a entrevistar a quienes compartieron alguna vivencia con ella, poniendo negro sobre blanco la leyenda de María la de Femés: Mararía.

Con sus aportaciones literarias, distintos autores han ido componiendo el imaginario paisajístico de Lanzarote. Por ejemplo: Agustín Espinosa con Lancelot $28^{\circ}-7^{\circ}$, José Saramago con Cuadernos de Lanzarote o Michel Houellebecq con Lanzarote. Desde una perspectiva regional, nos remitiremos a la mitología conductora propuesta en Lancelot, $28^{\circ}-7^{\circ}$. En las primeras páginas de su obra, que bien parecen ser una declaración de intenciones, Agustín Espinosa se presenta con una postura literaria distanciada del denostado paisaje de la isla de Lanzarote, que hasta entonces hubo sido constituido "de manera anecdótica, inafectiva" (Espinosa, 1988, p. 9). Con su Guía integral de una isla atlántica, sugiere una "literatura que imponga su módulo vivo sobre la tierra inédita" (1988, p. 9). En palabras del autor:

\footnotetext{
Mi intento es el de crear un Lanzarote nuevo. Un Lanzarote inventado por mí. Siguiendo la tradición más ancha de la literatura universal. Por eso sustituyo un Lanzarote que hoy ya nada dice, que ha perdido su sentimiento efectivo, por Lancelot. [...] Penumbro el vocablo popular para prosceniar el vocablo culto. Sustituyo lo concreto por lo abstracto. El molde, por el módulo. Lo entero, por lo íntegro. El objeto, por su esquema. El sujeto, por su esencia. La Isla, por su mapa poético. Culto. Construyo la geografía integral de Lanzarote (Espinosa, 1988, p. 10).
}

Ante una insensibilidad inveterada en la cultura popular, Espinosa decide transgredir la corriente regionalista de su era literaria universalizando el paisaje lanzaroteño, sustituyendo "una palabra -Lanzarote- ya sin sentido por otra llena aún de alto sentimiento de heroicidad" (1988, p. 10). De esta manera, propone una aculturación paisajística no solo para revitalizar la herencia literaria adherida a la cartografía isleña, sino para devolverle el arraigo al habitante, quien se hubo distanciado de su identidad por la abulia de residir en un aislamiento tan precario $^{3}$. Su ingenio aparece tanto al extrapolar la heroicidad de Odiseo al viento lanzaroteño,

2 Si bien el poemario se publica seis años después de la primera edición de Mararía (1973), en la conferencia del autor en la Escuela de Magisterio de Las Palmas, el 11 de diciembre de 1985, afirma: "Y no es aquí, en la novela, donde Mararía surge por vez primera. Ya con anterioridad devino predibujada entre tercetos como María de Femés, en un libro que titulé A la sombra de los cuervos, con temática de Lanzarote" (Arozarena, 1985, p. 12).

3 "La tradición, para los vanguardistas, es principalmente ruptura. La intervención de estos autores, en definitiva, se convierte, al plantear miradas sobre los paisajes que se superponen a los propios paisajes 
argumentando que existe "una relación hermética del héroe con el escenario de los hechos heroicos" (1988, p. 34), como al desentrañar en las salinas de Janubio una de esas "falsas postales lapónicas de Navidad" (1988, p. 75).

Por consiguiente, el escritor vanguardista establece un simulacro de lo que otrora pudo haber transcurrido en la isla, haciendo de ella "un hiperreal, el producto de una síntesis irradiante de modelos combinatorios en un hiperespacio sin atmósfera" (Baudrillard, 1978, p. 7). Literatura mediante, propugna un escenario irreal que salvaguarde el patrimonio tangible del territorio insular al que responde. Convida al habitante, y luego al visitante, a leer el espacio isleño desde una mirada ignota, liberada de indolencia que trascienda la realidad, procurando "hacer coincidir lo real, todo lo real, con sus modelos de simulación" (Baudrillard, 1978, p. 6). A través de la reinterpretación del externo real, Espinosa concibe un simulacro que traspone la idea original de la isla para enaltecer la identidad isleña. Procurando sanarle al habitante su desarraigo por una tierra "sin tradición fuerte, sin atmósfera poética" (Espinosa, 1988, p. 9), Espinosa consuma su mitología conductora dotando de un sentido universal al signo regional de Lanzarote ${ }^{4}$. Y de esta intencionalidad del escritor tinerfeño de perpetuar la imagen para preservar el signo, proviene la escritura del paisaje literario de Mararía.

Tal como ocurre con la aculturación paisajística de Espinosa, inscribir a la mujer en la literatura es adscribirle estereotipos que consolidan su legibilidad registrada en ese imaginario colectivo. En este sentido, si la literatura "participa de la construcción del paisaje" (Becerra Bolaños, 2010, p. 56) a la par que con ello "persigue cambiar la percepción que se tiene del lugar de manera palpable: lo intangible se convierte en tangible" (Becerra Bolaños, 2010, p. 56); no resulta descabellado aplicar este hecho a la constitución literaria de la mujer concreta. En esta estrategia, el creador literario se sirve de las referencias brindadas por la realidad para labrar maneras desacostumbradas de leerla. No obstante, una lectura no deja de gestarse en la voluntad hermenéutica de quien, subjetividad mediante, literaturiza la realidad, haciendo de ella un signo capaz de opacar su propia naturaleza en virtud de una mistificación:

Todo paisaje es una realidad interpretada y, en consecuencia, la lectura de un paisaje es siempre una metalectura. En el proceso de transformación del espacio en paisaje, y en el proceso de transformación del paisaje simple en complejo y del individual en cultural, la realidad corre el riesgo cierto de quedar postergada por el paisaje que la suplanta y que tiende a constituirse en realidad sígnica autosuficiente (Marrero Henríquez, 2009, p. 11).

En un contexto en que el discurso literario ha sido transmitido por el eco masculino, son innegables las similitudes entre la literaturización de la mujer y la trascendencia del paisaje literario. Partiendo de la verticalidad del sujeto que explica la presencia percibida del objeto, la descripción unilateral de su personalidad literaria se incrusta en tal medida a su identidad que la concibe inherente. Al traspasar la pluma del escritor, la literatura coloniza el territorio igual que coloniza la realidad de ser mujer encapsulando su identidad en arquetipos tendenciosos ${ }^{5}$.

y que acaban convirtiéndose en los paisajes mismos [...], en la lectura de la tradición y, por tanto, en tradición misma, por cuanto participan de los mismos procesos de escritura de quienes los precedieron" (Pérez Hernández y Becerra Bolaños, 2011, p. 86).

4 "Es la materialización del mito y cumple su función como modelo explicativo tanto para el propio como para el extraño, ya que es asimilado por la comunidad al ser incluido en su propio patrimonio sentimental, y acaba siendo, de alguna manera, objeto inventariable y, por tanto, digno de ser recordado por los viajeros" (Becerra Bolaños, 2010, pp. 429-430).

5 En la lógica masculinista que ha urdido el relato literario, la realidad de ser mujer conlleva todo un 
Como una lente adicional, "el paisaje vive sobre el lugar" (Marrero Henríquez, 2009, p. 11) en que se ha inspirado el discurso entretanto este espacio pervive. Al desaparecer, "el paisaje sobrevive al lugar" (2009, p. 11), pues las apreciaciones progresivamente inventariadas en el acervo literario se imponen a su esencia ${ }^{6}$.

\section{A cuerpos distintos, paisajes iguales: mujer e isla}

Como hemos venido anticipando, en el relato universal de la literatura, el escritor ha monopolizado la representación del mundo ${ }^{7}$. Mediante un discurso unilateralmente masculino, ha procurado explicar el mecanismo de la realidad a lo largo de la historia. Entre sus inquietudes, el hombre ha tratado de explicar a la mujer real creando y cincelando el personaje femenino a partir de un prisma personal, aunque cultural, que categoriza de acuerdo con un inventario maniqueo de literaturizaciones. Pero lo que en un principio se concibe como reflejo deviene espejo al diluirse el horizonte que discierne lo original de lo simulado. En consecuencia, el sentido resulta censurado por su propio signo debido al "poder mortífero de las imágenes, asesinas de lo real, asesinas de su propio modelo" (Baudrillard, 1978, p. 13). En sentido inverso al original, la mujer real queda reducida a un correlato directo de la hiperrealidad que representa la mujer literaturizada. Por consiguiente, su referente literario es un mapa que simula a la par que solapa el territorio de la referencia real, pues "el territorio ya no precede al mapa ni le sobrevive. En adelante será el mapa el que preceda al territorio" y, a largo plazo, "el que lo engendre" (Baudrillard, 1978, pp. 5-6).

Una de las imágenes inscritas en el espectro del eterno femenino es la isla. La mujer como referente de la tierra o del territorio es bastante recurrente en el relato universal de la literatura, donde se propende a delinear la naturaleza de la mujer real como se limitan las provincias en los mapas. Pero es que al trazar lo abstracto con la silueta de lo concreto, lo que se obtiene no es sino una parcela de la realidad, algo desplazado del todo al que pertenece. Se obtiene, en resumidas cuentas, una isla. En este sentido, tanto la mujer como el territorio han quedado reducidos a la tesitura del objeto que, debido a un silencio infligido, es explicado por el sujeto que detenta la palabra demiúrgica del enunciado. Entonces, la mujer representa en algunas ocasiones a la isla y la isla, en el resto de las ocasiones, a la mujer. Se trata, por consiguiente,

espectro de actitudes contradictorias que han ido labrando la identidad femenina de acuerdo a una aritmética maniquea estructurada en virtud de los intereses del sujeto hegemónico. Es pertinente recordar que un sistema igualmente maniqueo sostiene el pensamiento imperialista. En su detentada tesitura de dominante, el colonizador vertebra todo un discurso con que pretende persuadir al colonizado de que, por su condición primitiva, le corresponden ciertas inmanencias. Inmanencias que, aunque posteriormente desmentidas, han ido alienando su identidad, no solo como pueblo precolonial, sino individual. "JanMohamed (1985) matizó esta tesis, afirmando que la economía colonial se basa en la 'alegoría maniquea', que transforma la diferencia racial en diferencia moral y hasta incluso metafísica” (Segarra, 2000, p. 72).

6 "Lanzarote será la última morada de Lancelot y todos aquellos sitios que no han logrado que el hombre se arraigue, hasta el momento de la enunciación poética de Espinosa, cobran significación" (Becerra Bolaños, 2010, p. 428).

7 "Representación y construcción son dos cuestiones íntimamente imbricadas. El privilegio que los hombres se han atribuido en el desempeño de ambas actividades los ha hecho dueños históricos de los sistemas de representación y les ha dado el poder sobre esas dos actividades: la de construir el mundo y la de representarlo" (Suárez Briones, 2000, pp. 29-30). 
de la insularidad adscrita al personaje femenino que puede advertirse desde la antigüedad del discurso literario universal:

\footnotetext{
Entre otras islas 'femeninas' Ulises visita la 'isla-refugio' (la cueva de la matriz femenina) donde vive la maga Circe, la 'isla-hogar' de Ítaca donde Penélope teje los recuerdos de su esposo ausente, las islas Lípari donde moran las sirenas que atraen a los navegantes a sus orillas. Islas -en resumen- que, con sus forestas umbrías, húmedas y perfumadas nos recuerdan los secretos del cuerpo de la mujer con el cual el motivo de la isla se asocia (Aínsa, 2000, p. 10).
}

Esta insularidad no responde meramente a una representación allende lo literal del enunciado, sino que aparece reforzada por el retrato descriptivo que sobre el personaje va versando a lo largo de la obra escrita. Por consiguiente, nos es posible hablar del binomio islamujer mediante paradigmas de las letras canarias como los personajes femeninos de Dácil, Guayarmina, Thenesoya e $\mathrm{Ico}^{8}$. En sus relatos, todas ellas pertenecen a la nobleza prehispánica de las islas y todas ellas son conquistadas -al igual que el territorio al que representan- por el extranjero de ultramar ${ }^{9}$. Seducirlas conlleva la victoria del bando colonizador, puesto que, debido a esa virtud tan culturalmente feminizada que es la indulgencia -virtud considerada signo de debilidad, luego parte del binomio correspondiente a la mujer-, acaban actuando en beneficio del invasor. Sus historias presentan, pues, a mujeres literaturizadas que representan su suelo natal: la isla -al tiempo que la isla las representa a ellas. En consecuencia, existe una relación especular de aculturación, pues aculturarlas a ellas es aculturar el suelo del que proceden.

Respecto a esta literatura regional, puesto que ha sido gestada con base en un sentimiento de apartamiento debido a sus coordenadas geográficas, no es inusitado que el escritor, como sujeto preponderante del discurso literario insular, establezca paralelismos entre dos objetos literarios: el espacio y la mujer. En Mararía, el territorio insular no es el único escenario que comparten los personajes que van desarrollando la historia con sus retrospecciones. En su literaturización como isla, la protagonista es en igual medida el contexto narrativo por el que sus paisanos van localizando sus memorias. Al igual que la isla, Mararía es el paisaje compartido por los testimonios que componen el argumento, y el sentimiento que cada personaje le profesa bien parece responder a una relación de afectividad para con el entorno que, de alguna manera, no deja de vincularse con el concepto, tanto individual como colectivo, de patria. Por consiguiente, la leyenda de María de Femés proporciona consistencia a aquella mitología conductora con que Agustín Espinosa procura preservar, mistificación mediante, el patrimonio tangible de la isla de Lanzarote, pues, como bien citamos anteriormente, no deja de haber "una relación hermética del héroe con el escenario de los hechos heroicos” (Espinosa, 1988, p. 34).

Entre los personajes que vertebran con sus aportaciones la novela de Arozarena, dos de ellos destacan por conceptualizar a la protagonista en calidad de paisaje literario. En primera instancia, se encuentra el narrador, para quien "Mararía es larga y seca como la isla de Lanzarote" (Arozarena, 1983, p. 62). No son escasos los paralelismos establecidos entre la apariencia de la protagonista del presente de la voz narrativa y el territorio isleño. A través de los retazos biográficos que van componiendo la diégesis, el narrador labra un paisaje literario

8 Dácil de Antigüedades de las Islas Afortunadas (1604) de Antonio de Viana, Ico de El juicio de Dios o la reina Ico (1841) de Graciliano Afonso, Thenesoya de Thenesoya Vidina (1934) de Néstor Álamo y Guayarmina de Tirma (1947) de Juan del Río Ayala.

$9 \quad$ En el caso de Ico, es su madre Fayna quien mantiene un idilio con el extranjero, lo que hace de ella un dechado del mestizaje inminente y no un paradigma en relación directa con el esquema extranjero-nativa. 
de Lanzarote que se adhiere a aquella mujer "tal un negro ciprés, ahumada tea o cuervo en vertical" (1983, p. 153). Paradigma de esta simbiosis es el siguiente fragmento:

\begin{abstract}
Pero en la parte alta de aquel árbol requemado, algo surgía incandescente aún; algo como una brasa encendida surgía de aquellos ojos negros, árabes, jóvenes y hermosos. ¿Fuego? -me preguntaba yo mismo-. ¿Qué clase de fuego? ¿Acaso la ira? Contemplando aquellas ascuas fijas y resplandecientes pensé en un rostro terso y blanco y unos labios sensuales de leves rosas, dulces y tibios como las uvas de volcán. Años atrás, desde luego, años atrás, cuando por las cañadas de aquel cuerpo joven cruzaban los vientos alisios erizando el fino triguillo de la piel, formando las dunas arenosas del torso. Años atrás, desde luego. Antes que el mismo viento pasara huracanado sobre la arcilla y dejara el paisaje convertido en un erial desamparado y rugoso, antes que aquellos ojos se convirtiesen en pavesas de rabia, cuando el fuego surgía de la montaña y encendía la isla toda y los hombres salían de sus casas y atravesaban la noche pretendiendo carbonizarse en la extraordinaria ardentía. Entonces sí, entonces el fuego (Arozarena, 1983, p. 153).
\end{abstract}

En este pasaje, la voz narrativa coloniza el espacio insular a través del lenguaje literario, crea una estampa del paisaje que se imprime en la prosopografía de la heroína. Al plasmar la isla en su discurso, el sujeto observador consolida la imagen literaria del territorio y, a un tiempo, la de la protagonista. En este sentido, literaturiza el objeto observado al aplicarle en circunstancias literarias una perspectiva que proporciona contundencia a su legibilidad, entendiendo legibilidad como la impronta heredada de lecturas preliminares, de interpretaciones que han ido sepultando la realidad de que parten.

Masculino, al igual que el narrador, es el segundo personaje que nos concierne: Ermín Lo, galeno vascuence asentado años atrás en la isla. Sus recuerdos participan en la construcción de la geografía literaria del personaje de Mararía, en tanto en cuanto enlaza la descripción del paisaje con la caracterización de la protagonista:

\begin{abstract}
Me divierte observar el óxido que día tras día va destruyendo el hierro, el fruto que se pudre, la flor que se aja, la piel que se arruga, el viento que deshace la piedra hasta convertirla en polvo, los cuerpos que se encorvan, la tierra que se vuelve yerma, el sol blanqueando los huesos de lo que fue un magnífico ejemplar y, allá al final del desierto, el horizonte vacío años tras años por donde nadie ha de venir a salvarnos porque sería ridículo. Ésta es mi condena y aún me queda por ver cómo se apagan unos ojos, cómo se enfría del todo un volcán (Arozarena, 1983, p. 155).
\end{abstract}

Respecto a estas literaturizaciones de la mujer como elemento del paisaje, es inesquivable retrotraernos a las escrituras dedicadas al paisaje norteamericano en la historia de su literatura, en que los autores propenden a feminizar y sexualizar el territorio natural, conque no ha de extrañarnos que apareciera el concepto land-as-woman (Kolodny, 1973). Con este término, se esclarece la manera en que las lecturas feminizadas se han ido interpolando en la recepción cultural del paisaje ${ }^{10}$. En su estampa de mujer, las connotaciones atribuidas a la tierra son tanto maternofiliales como sensuales, pues "la tierra se convirtió en el foco para expresiones personalizadas y transpersonalizadas, o culturalmente compartidas, tanto de homenaje filial como de anhelo erótico" (1973, p. 169)11, habida cuenta de que "la designación verbal de la tierra como femenina inevitablemente implica a los escritores [...] en un examen

10 "[...] as three hundred years of American writing before it had asserted, the American continent did indeed seem to promise a daily reality of security and freedom from want within a feminine ambience of maternal abundance and erotic beauty. Such imagery is archetypal wherever we find it; to label it as fantasy or unconscious material is not thereby to dismiss it, but rather to recognize that fantasy is a particular way of relating to the world. R. D. Laing points out "It is part of, sometimes the essential part of, the meaning or sense [...] implicit in action" (Kolodny, 1973, p. 168).

11 "[...] the land became the focus for personalized and transpersonalized, or culturally shared, expressions of both filial homage and erotic longings" (Kolodny, 1973, p. 169). A partir de esta cita, las traducciones de esta obra son nuestras. 
de su propia reacción personal respecto a esta feminidad deseada” (1973, p. 173) $)^{12}$. En este sentido, y regresando a Mararía, la feminización del territorio insular de Lanzarote no deja de resultarnos insoslayable:

\begin{abstract}
Las mujeres defienden sus carnes forrándolas con telas oscuras, con faldas muy bajas y grandes sombreros de pleita. Contra la arena, el viento y el diablo, las mujeres embozan el rostro y dejan libre los ojos; eso sí, que sirven para apagar o encender el fuego, para que entre y salga el alma como una paloma. La isla es como una mujer. Tiene su fertilidad y hay que defenderla del diablo. Para ello le cubren el cuerpo con arena de volcán, piedra ya quemada contra la que el fuego no puede (Arozarena, 1983, p. 221).
\end{abstract}

El imaginario en que se circunscribe a la tierra se encuentra angostamente vinculado a los rasgos genéricos de la mujer, y viceversa ${ }^{13}$. Por ejemplo, se conquista un territorio igual que se conquista a una mujer. Se le adscribe a la tierra el carácter de fertilidad o de esterilidad de acuerdo con su potencial de producción natural. La pureza atribuida a la virginidad femenina es igualmente extrapolable a la esencia inmaculada del sustrato. Se habla de madre patria para designar el suelo natal y de madre naturaleza para denominar el entorno natural. En consecuencia, esta proclividad literaria evidencia que "tanto la mujer como la tierra se conciben como territorios a ocupar [sic], pasivos, a la espera, que sólo mediante la actuación del hombre puede adquirir valor" (Martín Lucas, 2000, p. 163). Y dentro del catálogo de este imaginario, el de la isla es el paradigma más palmario, tanto que no ha de extrañarnos que el propio autor de Mararía enunciara de su opera prima lo siguiente:

Por eso y recordándoles una vez más que el mar no es divisible, el material con que ha sido hecha Mararía he tenido que buscarlo en las lavas del interior isleño, donde gracias al fuego, que ya me figuro corazón ardoroso, la isla eclosiona con su doble imagen de mujer (Arozarena, 1987, p. 14).

A continuación, atenderemos algunos testimonios que la voz narrativa va hilvanando a lo largo de la lectura. Escrutaremos las aristas del retrato poliédrico que de la heroína alberga la novela para concluir esclareciendo la voluntad del discurso masculino de literaturizar a la mujer como un paisaje literario, por tanto como hiperrealidad circunscrita -o susceptible de circunscribrirse- al imaginario colectivo. Y es que en absoluto resulta complicado advertir que en nuestra protagonista se inscribe el mitologema de un paisaje literario que participa de la mitología conductora postulada por Agustín Espinosa (1988), pues "Mararía a poco que se la observe, es también la isla de Lanzarote” (Arozarena 1983, p. 14).

\title{
3. Las voces de Femés: una semblanza de Mararía
}

Con la salvedad del recuerdo de la esposa del alcalde de Femés, son inexistentes los testimonios con voz de mujer a lo largo de la lectura, pues es el propio narrador quien las reporta mediante otros personajes. Apelando a la perspectiva femenina, hemos de comenzar con una de las vecinas que repudian a Mararía: Delfina. Se trata de una mujer corpulenta a quien la esposa

12 "The verbal designation of the land as feminine inevitably involved the writers [...] in an examination of their own personal reaction to that desired feminity" (Kolodny, 1973, p. 173).

13 Lejos de tratarse de una cuestión meramente lingüística, a sabiendas de que en español los géneros relativos a las voces de tierra y mujer son femeninos, huelga destacar que en inglés, lengua que carece de género gramatical para designar la voz land, se recurre igualmente al pronombre personal she para referirse a la tierra. Esto puede advertirse ya en esos textos literarios del siglo XVII sobre el paisaje norteamericano, donde existe una "initial response to the American continent as Woman -be she Mother or Virgin” (Kolodny, 1973, p. 180). 
del alcalde le dedica algunas palabras nada lisonjeras en su recapitulación sobre las nupcias de la protagonista. Ante el rezago del prometido, Delfina ridiculiza la espera de la protagonista. Al no producirse su llegada, "empezó a aplaudir y a gritar con mucha mala fe: ‘Que viva la novia!"” (Arozarena, 1983, p. 91), y mientras repartía el vino entre los invitados "no dejaba de brindar por la novia" (1983, p. 91). Puesto que no la conoce, no entiende a la protagonista ni quiere intentarlo. En su ignorancia encuentra seguridad, aun cuando la censura. La de Delfina es la voz de las mujeres casadas de Femés, de esas comadres que han espiado la soledad de Mararía para luego propagar rumores que aseguran "haberla visto amamantando, unas dicen que a lagartos y otras a murciélagos" (1983, p. 62). De este prototipo de mujeres la voz narrativa anticipa que "tienen la culpa de lo que pasa en el pueblo" (1983, p. 62).

Otra de las lugareñas que no tiene en buena estima a Mararía es seña Carmen, la madre de Isidro. Su percepción de Mararía no procede de su propio testimonio, sino que resuena en el relato de Manuel Quintero, quien visita por vez primera el pueblo de Femés en compañía de su amigo Pedro el Geito. Tras preguntarle por el paradero de la protagonista, Pedro comienza a conversar con seña Carmen, quien dice de ella que "ha trastornado a los hombres y va a traer desgracias", pues su "hijo anda enfogueteado por esa mujer, que no parece sino que tiene maleficio en los ojos" (Arozarena, 1983, p. 73). Para la madre de Isidro, Mararía es la responsable de los desatinos no solo de su hijo, sino de los hombres del pueblo. Al trasegar a sus paisanos con ella, considera que su belleza es la culpable de las desdichas venideras, no solo de la propia protagonista, sino de la gente del pueblo. Su vaticinio, representativo de la mentalidad de antaño, se encuentra sesgado por un discurso que libera al hombre de la responsabilidad de sus deslices al percibir a la mujer como la portadora de las tentaciones ${ }^{14}$. Huelga recordar que el propósito principal por el que su madre lo manda a trabajar a la hacienda de don Lázaro, localizada en otro pueblo, no es otro que apartarlo de aquella "condenada" que tiene a su hijo "enfogueteado". Aunque de mujer, es la voz del patriarcado, la voz de todas esas comadres que contribuyen con sus prejuicios a construir la malograda reputación de María de Femés, que se transmite irremisiblemente de generación en generación.

Durante los años ulteriores a la guerra civil, la Sección Femenina de la Falange Española, dirigida por Pilar Primo de Rivera, es el organismo entregado a preservar el puritanismo propio del régimen a partir de la consolidación de las convenciones sociales sintetizadas en la mujer de la época. Para alcanzar esta categoría, era necesario que dispusiera de todas las virtudes catalogadas en el constructo de su femineidad. "La función de la mujer era esencial, pues por medio de la maternidad servía como 'tabernáculo de la raza que siempre se renueva" (Pelka, 2014, p. 28). El utilitarismo procreativo que se le impone al colectivo femenino es a la casta lo que el territorio es a la patria. Entonces, la estrategia más efectiva de garantizar al sistema la pureza de la raza es controlando la sexualidad femenina a partir de la censura del cuerpo, haciendo de su puesta en escena un estatuto. A fin de cuentas, la mujer

14 El 25 de agosto de 1936, el diario El Pensamiento Navarro publica: "Cubre tus carnes, mujer. Estamos en la guerra. La guerra es un castigo de Dios por nuestros pecados. Los hombres hemos pecado, señor, pero ahí tienes la sangre de nuestros varones. ¡Cuántos jóvenes que por ti pecaron, mujer, han muerto! Por tu causa, por tus carnes desnudas, por los brazos sin ropa, por tus pechos descubiertos [...]. Arregla los vestidos indecentes, quémalos si puedes hacerte con otros. Así destruirás parte del escándalo que has sido. No se te pide sangre, como sí les pide a los hombres la Patria. ¡Adelante, mujer, no quieras pecar más. No sea que te suceda otra cosa peor!” (González Duro, 2012, p. 18). 
aspiraba a ser carne de una idealización, a transmutarse en materia de la mitología conductora que sobre ella pesaba. En este sentido, no solo se hace política con el suelo, sino con la mujer, quedando reducida a la categoría de objeto para enclaustrarla en una personalidad tendenciosa que sirviera de imagen de los intereses de la patria.

Respecto a las niñas de Femés, es menester reparar en el repudio que les suscita la sola estampa de Mararía. Debido al misterio que destila su voluntad de destierro social, corean canciones inspiradas en las presuntas aptitudes de brujería de la protagonista. Tras su muerte, una de las niñas se disgusta cuando las otras la parangonan con ella con intenciones burlescas y "la niña-bruja se echó a llorar. Sintió como si se hubiera muerto y volara entre los vilanos que llenaban ya el cielo de Femés" (Arozarena, 1983, p. 227). En este sentido, la condición ultraperiférica de la isla se encuentra plasmada en el aislamiento de la protagonista durante su vejez. La soledad de Mararía es la soledad de los isleños, de los habitantes de un territorio rodeado de agua por todas partes ${ }^{15}$. Por su trascendencia, los imaginarios se consolidan mediante actitudes reiteradas que se sostienen sobre concepciones residuales. La reproducción individual de los preceptos transmitidos garantiza la aceptación en una comunidad cultural, en un sistema social. Por ello, la repulsa que la protagonista produce en el personaje de Delfina -paradigma nacional de la mujer de entonces- se propaga en las generaciones venideras. Por consiguiente, partiendo de la premisa de que Mararía representa la isla de Lanzarote, el desprecio no solo adopta la medida del repudio hacia la mujer, sino del desarraigo por la isla.

Este mecanismo de trascendencia intergeneracional opera de igual manera con cualquier ideario, como sucede con la perpetuación del paisaje literario. En este caso, ambas hiperrealidades, la de la mujer como constructo cultural y la del paisaje como lectura del entorno natural, beben del mismo manantial: la literatura. Las dos creaciones participan del territorio nacional, en tanto se les ha detentado su realidad en virtud de un artificio político. Se apelan a las virtudes procreativas del eterno femenino para ensalzar el retrato público de la mujer, quien "se miraba en el espejo de la Virgen María" (Pelka, 2014, p. 41). En lo que a la protagonista respecta, es despreciada por tratarse de aquello en que el pueblo no quiere que se convierta Lanzarote. Al entregarse a lo desconocido, al visitante, se desliga de lo conocido, del isleño, y esto, a su vez, la desmerece como participante del género sistematizado por el régimen ${ }^{16}$.

El ideario femenino del nacionalsindicalismo estaba vinculado a la posición social de la mujer, así como a unas claramente definidas virtudes caracterizadoras. En primer lugar, "la mujer de España, por española, [era] ya católica". La concepción constituía, al igual que en otras dictaduras fascistas, su deber principal: "La verdadera misión de la mujer es dar hijos a la Patria. Y ésta es, por lo tanto, su suprema aspiración. Y dentro del nacionalsindicalismo, sigue siendo más que nunca su misión ser la continuadora de la raza, de los caminos que abrieron aquellas mujeres de las islas tienen carácter funerario, como Calipso. Pudiera acaso establecerse la ecuación (en contraposición e identidad) de la isla y la mujer, como la del monstruo y el héroe" (Cirlot, 1994, p. 254). "La asimilación de tendencias extranjeras fue desde un principio repudiada por antifemenina" (Pelka, 2014, p. 35). Si bien la autora de estas palabras habla de moda al referirse a las "tendencias extranjeras", es palmario que todo lo localizado a las afueras de los límites territoriales del estado, todo lo que no obedezca al código cultural pertinente, es destinado a una alteridad consecutivamente denostada. De hecho, en la revista del régimen franquista Y. Revista para la mujer (1934), el dramaturgo español Enrique Jardiel Poncela redacta una suerte de listado sobre las cinco tipologías de mujer existentes que, a su vez, identifica de acuerdo a un espectro cromático sumamente personal. De las mujeres lilas postula que "encontraban cursi todo lo español y distinguido todo lo extranjero" (1938, pp. 36-37). 
que se llamaron Isabel de Castilla y Teresa de Jesús, en cuyas vidas encontramos tanto amor hacia Dios y a la Patria (Pelka, 2014, pp. 26-27) ${ }^{17}$.

Durante la dictadura, la mujer es instada a ser un simulacro de referentes nacionales que han personificado las directrices femeninas del fundamentalismo cristiano. Apelando a su potencial reproductivo se la hace participante de la prosperidad nacional mediante el establecimiento de la raza española. A partir de la mujer abstracta, que es la hiperrealidad a la que está subordinada la mujer real, se va difuminando el referente concreto al igual que el paisaje literario, elemento intangible, se sobrepone al espacio objetivo, compuesto tangible. A toda costa ha de alcanzar el modelo irrebatible de una entelequia cincelada, de una parte, por el relato creacionista del culto cristiano y, de otra, por los decretos heteropatriarcales del partido nacionalsindicalista. En otras palabras: ha de encarnar el repertorio de cualidades encapsuladas y destinadas culturalmente a su sexo en el imaginario colectivo. Su carga mitológica adquiere corporeidad a través de ella. Para la España de Franco, la mujer española por excelencia es "la que no tiene pasado y cuida en todo instante de su presente, porque sabe que lleva dentro de sí misma el porvenir. Es decir, la que ha hecho real lo ideal" (Jardiel Poncela en Sevillano Calero, 2007, p. 112). Hacer real lo ideal o vestirse de todos los mitologemas que la han precedido a fin de transmutarse en otra hiperrealidad al gusto del gobierno de turno, sustituyendo "lo concreto por lo abstracto" y “[e]l objeto por su esquema” (Espinosa, 1988, p. 10).

En lo que concierne a nuestro discurso, la protagonista, a medida que se desvincula de Femés y se aproxima a la alteridad, se va distanciando de la normatividad, lo que la conduce a ser humillada impunemente, no solo por la voz de la mujer adulta, sino por su eco en las mentes de las niñas. En las dimensiones públicas, el escarnio, siempre que estuviera vinculado con lo subversivo, estaba absolutamente permitido. Vivir de acuerdo al juicio ajeno era, pues, la estrategia con la que el sistema se procuraba la obediencia civil y la integridad de sus principios ideológicos.

Recurriendo a la perspectiva masculina, Isidro es el hijo de seña Carmen, la propietaria de la venta de Femés, quien, durante la retrospección narrativa, lo encomienda a don Lázaro, propietario en la hacienda La Cantarrana, en un pueblo llamado Uga. Lucía, la sobrina del terrateniente, se enamora de Isidro. Lejos de desearla como mujer, acaso por estar "delgada como un tallo de trigo" (Arozarena, 1983, p. 120), vislumbra oportunidades de riqueza en el posible noviazgo. Pese a no sentirse enamorado, Isidro se compromete con Lucía con la aquiescencia de don Lázaro, ignorando su tío que estaba encinta del hijo de seña Carmen. En mitad de estas circunstancias tan propicias para las pretensiones del capataz, comparece María buscando trabajo en la hacienda. Con la presteza propia del enamorado, Isidro se lo concede. Al acabar de trabajar, Isidro la aguarda en el sendero por donde María regresa a Femés. Una vez terminada la conversación, Isidro concluye que a María "más que dinero le faltaba un hombre que la quisiera de veras, un hombre capaz de proteger su hermosura; alguien con quien desahogar las razones de aquel llanto que [vio] asomar a sus ojos" (1983, p. 137). En definitiva: "un hombre para defenderla de aquella soledad que la amenazaba y para toda la vida" (1983, p. 137). Al igual que una isla parece precisar de alguien que le asigne el apelativo de patria como justificación de que se la preserve del forastero, Mararía necesita, a ojos de este personaje, de un

17 Citando los números 68 de Y. Revista para mujeres (1943, p. 40) y 69 de Medina (1942, p. 2) respectivamente. 
hombre que la proteja y consuma su condición de mujer. Por consiguiente, Isidro le hace creer a María que está dispuesto a ser el hombre que la rescate "por ver si de una vez caía en [sus] brazos y saciaba aquel apetito que, de años, [le] traía a mal dormir" (1983, p. 136). No obstante, antepone sus intereses económicos en detrimento de "aquella mujer que nunca [supo] si era ángel o diablo" (1983, p. 137), lo que hace que la protagonista le clave un cuchillo en el hombro y lo abandone a la intemperie "perdiendo el malvasía" (1983, p. 145).

Prosiguiendo con el decurso del relato, nos encontramos con don Abel. Aunque antiguo sacerdote de Femés, en la actualidad narrativa reside en la ermita de San Cristobalón. De no haber sido por el homicidio del prometido, perpetrado por los hombres del pueblo, hubiera oficiado su enlace con María. Hemos de atender a su primera intervención para comprender su relevancia en este discurso:

\footnotetext{
-Aquí, en esta ermita, surgió también la Bestia ante mis ojos...

Quedó el anciano mirándome con fijeza por ver si me reía. Yo sostuve el taladro de su mirada con perfecta gravedad. -... y esa vez se llevó todo lo que había engendrado. Su propia máscara, la belleza, el sexo y el fruto de la mujer encinta. La mujer que vino a mí con alas de águila y que yo alimenté durante mil doscientos sesenta días (Arozarena, 1983, p. 198).
}

Con estas palabras, el sacerdote introduce su testimonio al narrador. Entre el escepticismo y la demencia, le habla de la "Bestia" desoladora que, agazapada en el cuerpo de una bella mujer, lo depuso de su lucha ${ }^{18}$. Recién instalada en San Cristobalón, don Abel se extraña una mañana al no encontrar preparado el desayuno y decide irrumpir en la alcoba de Mararía. "Sobre la cama estaba tendida como Dios la echó al mundo. En sus ojos sostenía una mirada penetrante, como un desafío. Era simplemente una mujer desnuda, una estúpida artimaña del demonio" (Arozarena, 1983, p. 201). Como hemos ido advirtiendo, el tonsurado no es el primer personaje masculino que parangona la mirada de Mararía con un desafío, pues, al parecer, Mararía portaba consigo "una luz incitadora en los ojos" (1983, p. 201). En efecto, aquella "estúpida artimaña del demonio" resulta ser una estratagema para cerciorarse de la decencia de aquel hombre que le hubo prestado cobijo.

Como hemos apuntado con anterioridad, en el régimen franquista, la identidad social de la mujer -concebida como entidad cultural- se labra atendiendo a los designios tanto de la Iglesia Católica como de la Sección Femenina. Esta última se retroalimenta de los principios dogmáticos de la primera, derivando en un matrimonio político estrechamente consolidado. De acuerdo con la autoridad eclesiástica, el cuerpo femenino es portador de tentaciones carnales que eran necesarias censurar, no solo a partir de actitudes heterodoxas, sino mediante un protocolo indumentario que garantizara el decoro cristiano (Pelka, 2014). En consecuencia, se le designan imperativos morales basados en el puritanismo galopante de siglos atrás. Entonces, y derrocando los resultados progresistas obtenidos durante la Segunda República, el cuerpo de la mujer vuelve a concebirse como propiedad de un sistema natalista, luego como parte de la patria que preserva el territorio nacional. Experimenta una suerte de aculturación por parte del gobierno pertinente: lo que se hubo concebido como mujer en el sistema derrocado es relegado a los márgenes en virtud del concepto aséptico y blindado de la mujer española. Por supuesto,

18 De acuerdo con la entrada de Bestia apocalíptica del Diccionario de símbolos (Cirlot, 1994, p. 9): "A veces se ha identificado con el principio femenino, en cuanto éste es fuente de tentación y de corrupción, pero, principalmente, de estancamiento en el proceso evolutivo". 
su anatomía también alberga sombras desprendidas del mitologema de Eva, lo que hace de su persona responsable del uso que el hombre haga de ella:

Respecto al cuidado corporal, Enciso Viana consideraba que las mujeres pecan de presunción: "Esa belleza no es tuya; Dios te la dio para que fuese un reflejo de su belleza divina, y al contemplarte los hombres encontrases en ti un medio de ir hacia Él; y tú, olvidada de Dios, te atribuyes esas bellas cualidades y las utilizas para atraer a los hombres hacia ti apartándoles de Él” (Pelka, 2014, p. 35).

La personalidad de don Abel corresponde con el ideario de la comunidad católica. En unas circunstancias sociopolíticas donde la corporalidad de la mujer es estigmatizada para reducirla a un elemento del patrimonio nacional cuya utilidad primera es propagar la raza, la femineidad no deja de ser un producto politizado al servicio del espectro de valores nacionales que, a pesar de contadas discrepancias, responde a la voluntad clerical. Un producto, a fin de cuentas, tan politizado como el contorno cartográfico del estado. Pues "España quiere que sus mujeres le sirvan únicamente como mujeres. Que 'hagan patria' únicamente como mujeres" (Carmen de Icaza en Sevillano Calero, 2007, p. 109).

En la historia que nos atañe, y coincidiendo con la visita de la protagonista al sacerdote, se celebra la onomástica de San Cristobalón a la que acuden paisanos de distintos pueblos de la isla. Al terminar, permanecen unos hombres a quienes el sacerdote identifica como ratones ${ }^{19}$. Entre ellos, se encuentra don Bartolo, quien comienza a proferir comentarios inapropiados a don Abel: "Y usted, don Abel, ¿con quién se retirará esta noche? ¿Con Dios? ¿O acaso con ese diablo tan bonito? (Arozarena, 1983, p. 203). Tras esta pregunta, se origina una contienda entre el cura y los convidados, quienes se dirigen hacia la ermita donde se encuentra la protagonista:

\footnotetext{
Tenía en la mano un cirio encendido y quedó inmóvil, desafiando a los ratones con una mirada satánica. El tiempo pareció cumplirse, pues en aquel instante, la Bestia hizo su aparición y repentinamente y ante el asombro de todos, envolvió con su manto rojo y luminoso la figura de la mujer. En verdad fue sorpresa porque yo no esperaba que la Bestia surgiese en aquel momento, ni tenía idea de lo que buscaba allí. Claro que si María se hubiese confesado conmigo, si me hubiera dicho que en sus entrañas... (Arozarena, 1983, p. 204).
}

Ante los estragos ineludibles que desencadena su belleza, Mararía prende fuego a su cuerpo, matando en consecuencia a la criatura de la que estaba embarazada. Don Abel vislumbra a la Bestia en el sacrificio de la protagonista, aunque no lo perciba como tal, pues "Luzbel fue más diablo siendo un ángel bello que después, convertido en Satanás” (Arozarena, 1983, p. 201). En este pasaje, asistimos a una anagnorisis del personaje principal. La de Femés decide recuperar la pertenencia de su corporalidad a través del exterminio de su cuerpo, de aquello por lo que quedaba conceptualizada como un mero estandarte representativo del universo de Femés. En su legibilidad registrada a lo largo de los siglos, el fuego implica, sufrimiento mediante, una catarsis, un proceso que garantiza una metamorfosis. Se trata de una renuncia de las lecturas hacinadas en lo tangible de su persona obteniendo una reescritura de lo intangible de su personalidad. En definitiva: la decisión de la protagonista de quemarse consiste en su manera de empoderarse reapropiándose de su corporeidad, luego de su identidad, expoliada por el dominio popular. Sin embargo, la inmolación de su propia belleza y, en consecuencia, de su criatura la transfigura en la imagen terrenal del demonio a ojos del clérigo.

19 El simbolismo del ratón no solo "es asimilado al demonio" (Cirlot, 1994, p. 382), sino que igualmente "[s]e le superpone significado fálico, pero en su aspecto peligroso y repugnante” (Cirlot, 1994, p. 382). 
En el imaginario colectivo de la isla de Lanzarote, el fuego presenta un signo especial. Apartando la relación evidente entre este episodio y la sentencia en la caza de brujas de la Iglesia Católica, la estampa de la protagonista devorada por las llamas corresponde con la representación cultural de Timanfaya, volcán que en reiteradas ocasiones soterra el territorio isleño bajo el malpaís que hogaño configura su paisaje literario. Relativo a este accidente geográfico es el párrafo que inaugura este capítulo, en el que la voz narrativa principal no solo prosigue con la escritura del paisaje literario de la isla, sino que se sirve de una de las prolepsis tan recurridas por el autor a lo largo de la diégesis que constata la conjunción del paisaje con la mujer:

Trasponía el sol las chatas montañas, blancas y negras colinas de Saimor, Cerro de los Palomos y Santa Catalina, volcán. Por la llanura de jables y caliches corrían las sombras de los montes como tres dedos negros. Atrás, lejos aún, venía la sombra grande, la sombra de Timanfaya, que ya no es ni sombra ni cordillera. Por allí está la Montaña del Fuego, que es el corazón y permanece caliente como si la isla recién acabase de morir (Arozarena, 1983, p. 189).

Como si en un presagio consistiera, la voz narrativa destaca "la sombra grande, la sombra de Timanfaya". Seguidamente, localiza la Montaña del Fuego, que "permanece caliente como si la isla recién acabase de morir". En este sentido, el fuego relaciona las muertes de dos paisajes, aunque originalmente distintos, literariamente iguales: el cuerpo de la isla y el cuerpo de la mujer. Y es que la protagonista

habiendo sido una mujer hermosísima, ella misma se pone en contra de su belleza y se quema, para destruir esa belleza física que pertenece más al diablo, y que el hombre que después la quisiera tendría que hacerlo por ella misma, no por su belleza corporal, Mararía se autoquemó para destruir su belleza, como Lanzarote se calcinó con el fuego que extrajo de sus volcanes (Arozarena en García de Mesa, 2004, p. 58).

Otro de los personajes masculinos que declara su malquerencia hacia la protagonista es Pedro el Geito, el conductor de la camioneta que transporta a los habitantes de Lanzarote de pueblo en pueblo. Al llegar a la isla, este personaje lleva al narrador a las inmediaciones de Femés. Para su desconcierto, se niega en rotundo a entrar al pueblo por supersticiones inspiradas en antiguas vivencias. En un episodio posterior, el narrador y Manuel Quintero se tropiezan en una venta de Uga con este personaje, antiguo compañero de barco del segundo. Al preguntar si puede alcanzarlos a Femés, Pedro le responde que no piensa pisar Femés mientras allí habite "aquella maldita bruja" (Arozarena, 1983, p. 82). Para este personaje masculino, al igual que para el resto de sus paisanos, Mararía "es una mujer maldita" (1983, p. 82).

En su juventud, Pedro asiste a un baile de Femés y convida a bailar a Mararía, pero rechaza su proposición "con un gesto como si le apestara la cercanía de aquel hombre" (Arozarena, 1983, p. 75). Tras el desplante por parte de la protagonista, Isidro le recuerda:

\footnotetext{
- Ya sabes que María no baila.

- Pues no sé a qué coño viene entonces.

- A ver bailar a las otras - dijo Isidro.

$-\mathrm{Y}$ a encender candela. A eso viene.

Dijo esto y escupió con rabia. Luego añadió:

- ¿Es una perra! (Arozarena, 1983, p. 75).
}

Cuando los hombres de Femés hablaban de la protagonista, entre ellos Isidro y Alfonso, no escatimaban en ofensas. Tras enterarse de que iba a contraer matrimonio con el árabe, salieron del pueblo y se lanzaron sobre el prometido hasta darle muerte. A Pedro, el pensamiento que le consolaba era que aquel forastero "ya no podría llevarse a la María" (Arozarena, 1983, p. 86). Al parecer, "la María" era patrimonio exclusivo de los hombres de Femés. Limitaban con dominio paternalista los designios de su libertad. De igual manera que el hombre preserva su patria del 
invasor, la protegieron de la amenaza que significaba para ellos su enlace con aquel hombre a quien solo se llega a conocer por su gentilicio.

Esta violencia hacia el extranjero por parte de los habitantes de Lanzarote corresponde con la xenofobia inveterada en el discurso sublimatorio de la raza, tendencia generalizada en los gobiernos conservaduristas, como sucede durante la posguerra española, que desmerecen a las "muchachas que encontraban cursi todo lo español y distinguido todo lo extranjero" (Enrique Jardiel Poncela en González Duro, 2012, p. 29). En este relato, la protagonista no puede casarse con un hombre que no pertenezca, si no al pueblo, cuando menos, a la isla. El colectivo masculino decide los contornos de su destino, pues, como concepto cultural, al igual que la tierra, participa del patrimonio insular ${ }^{20}$.

\section{Conclusiones}

Acotado en un contexto literario, el paisaje no deja de ser un retazo del territorio al igual que el personaje femenino es una representación parcial de la mujer real. No obstante, la recepción del entorno resulta condicionada por sus literaturizaciones, solapando lo real por lo simulado, tal como sucede en el caso de la mujer concreta transmutada en mujer abstracta. En ocasiones, las lindes con que se disciernen los imaginarios de estos dos conceptos se desdibujan, haciendo que los rasgos de uno sean reconocibles en el otro. De esta manera, la realidad se convierte en un campo de simulacros que a partir de ella se han engendrado.

Con esta tendencia literaria no solo se feminiza el territorio, sino que se cosifica a la mujer a partir de atributos telúricos que la reducen a un paisaje literario, como ocurre con las descripciones que nos conceden el narrador y el personaje de Ermín Lo, quienes columbran a la protagonista en el territorio insular. En este sentido, en el paisaje quedan impresas cualidades inscritas en ese eterno femenino que encorseta la identidad culturalmente estipulada de la mujer, hecho que encontramos plasmado en el concepto land-as-woman. Esta reciprocidad, a su vez, se incrustra en el repertorio de mitos que se van sucediendo y retroalimentando unos a otros, en esa mitología conductora que constituye los imaginarios colectivos, luego las ideologías.

Respecto al ideario de la posguerra española, dos son sus promotores principales: la Iglesia Católica y la Sección Femenina. El dogma judeocristiano, encarnado en el personaje de Don Abel, sirve de sustento al organismo falangista, representado por el colectivo de las mujeres del pueblo de Femés, así como las niñas. Partiendo de las lecturas que las sagradas escrituras han realizado del papel de la mujer en la historia, se propaga un retrato sublimatorio que ha de materializar, no solo en las dimensiones públicas, sino en la intimidad del hogar. El sistema recurre al dominio de su corporalidad para restringir su sexualidad a su potencial procreativo, luego su voluntad queda al servicio de los imperativos morales de la patria. De transgredirlos, la mujer es descatalogada del inventario de hiperrealidades que sobre ella versan y destinada al escarnio, no solo público, sino incluso mediático. Este es el caso de la heroína de la novela que

20 [E]1 arquetipo de mujer promovido por la España de la posguerra redujo a ésta a su labor de esposa, madre y ama de casa, subordinada al hombre a todos los efectos económicos y sociales. La mujer era percibida en relación con su cuerpo, destinado a dar hijos en aras de la continuación de la "raza". En este aspecto de la bio-politica ocupa un lugar preferente el discurso sobre el cuerpo, incluido lo relativo a la belleza y la indumentaria femeninas (Pelka, 2014, p. 41). 
ha fundamentado nuestra tesis, que es repudiada por los habitantes de Femés por priorizar su libertad a la normatividad de entonces.

\section{Bibliografía}

Azul. (1942). No hay nada más bello que servir. Medina, 69, p. 2.

Aínsa, F. (2000). Islario contemporáneo. Espejo de paciencia: revista de literatura y arte, 5, 9-15. Arozarena, R. (1983). Mararía. Santa Cruz de Tenerife: Interinsular Canaria.

Arozarena, R. (1985). Motivaciones literarias de Lanzarote. Conferencia del autor en la Escuela de Magisterio de Las Palmas. Las Palmas de Gran Canaria.

Arozarena, R. (1987). Motivaciones literarias de Lanzarote. Guiniguada, 3, 7-16.

Augé, M. (2013). Naturaleza, cultura y paisaje. Revista Colombiana de Antropología, 49(2), 223-238.

Baudrillard, J. (1978). Cultura y simulacro. Pedro Rovira. Kairós: Barcelona.

Becerra Bolaños, A. (2010). Paisaje y memoria literaria. Anuario de Estudios Atlánticos, 56, 425-446.

Cirlot, J. E. (1994). Diccionario de símbolos. Barcelona: Labor.

Espinosa, A. (1988). Lancelot, $28^{\circ}$ - $7^{\circ}$. Guía integral de una isla atlántica. Tenerife: Interinsular.

García de Mesa, R. (2004). Conversaciones con Rafael Arozarena. Tenerife: Benchomo.

González Duro, E. (2012). Las rapadas: El franquismo contra la mujer. Madrid: Siglo XXI de España.

Houellebecq, M. (2000). Lanzarote. Barcelona: Anagrama.

Jardiel Poncela, E. (1938). Mujeres verdes, mujeres rojas, mujeres lilas, mujeres grises y mujeres azules. Y. Revista para la mujer nacionalsindicalista, 6 y 7, 36-37.

Kolodny, A. (1973). The land-as-woman: Literary convention and latent psychological content. En Women's Studies (pp. 167-182). Great Britain: Gordon and Breach Science Publishers.

Marrero Henríquez, J. M. (2009). Introducción. En J. M. Marrero Henríquez (Ed.), Lecturas del paisaje (pp. 9-15). Las Palmas de Gran Canaria: Universidad de Las Palmas de Gran Canaria.

Martín Lucas, M. B. (2000). Mujer y nación: construcción de las identidades. En B. Suárez Briones y M. B. Martín Lucas (Eds.), Escribir en femenino (pp. 163-178). Barcelona: Icaria.

Pelka, A. (2014). Mujer e ideología en la posguerra española: Feminidad, cuerpo y vestido. Historia Social, 79, 23-42.

Pérez Hernández, N. y Becerra Bolaños, A. (2011). Creación vanguardista de espacios dislocados: Canarias y Guinea, de Agustín Espinosa a Agustín Miranda. Iberomania, $73,76-89$.

Saramago, J. (1997) Cuadernos de Lanzarote. Madrid: Alfaguara. 
Segarra, M. (2000). Feminismo y crítica postcolonial. En M. Segarra y A. Carabí (Eds.), Feminismo y crítica literaria (pp. 71-94). Barcelona: Icaria.

Sevillano Calero, F. (2007). Rojos. La representación del enemigo en la Guerra Civil. Madrid: Alianza.

Suárez Briones, B. (2000). La segunda ola feminista. Teorías y críticas literarias feministas. En B. Suárez Briones y M. B. Martín Lucas (Eds.), Escribir en femenino (pp. 25-38). Barcelona: Icaria.

Ysern, A. (1943). Alabanza y homenaje a nuestras mujeres de Acción Católica. Y. Revista para la mujer nacional sindicalista, 68, 40-41. 
